\title{
The Effect of Word Type on the L1 Support for L2 Vocabulary Learning: The Case of Arab EFL Learners
}

\author{
Dina Abdel Salam El-Dakhs ${ }^{1}$, Hind ElHajj ${ }^{2} \&$ Jawaher Nasser Al-Haqbani $^{3}$ \\ ${ }^{1}$ College of Humanities, Prince Sultan University, Saudi Arabia \\ ${ }^{2}$ Deanship of Educational Services, Prince Sultan University, Saudi Arabia \\ ${ }^{3}$ Evaluation and Academic Accreditation Center, Prince Sultan University, Saudi Arabia \\ Correspondence: Dina El-Dakhs, College of Humanities, Prince Sultan University, Saudi Arabia. E-mail: \\ ddakhs@psu.edu.sa
}

Received: February 1, 2018 Accepted: February 24, 2018 Online Published: March 17, 2018

doi:10.5539/ijel.v8n4p25 URL: https://doi.org/10.5539/ijel.v8n4p25

\begin{abstract}
There is strong agreement in the literature that the first language (L1) supports second language (L2) vocabulary learning particularly at early stages of learning. The present study examines the influence of word type on the use of L1 language to support L2 vocabulary learning. To this end, 130 Arabic-speaking tertiary elementary female learners of English were taught 24 unfamiliar English words in 4 sessions over 4 weeks. The participants were divided into three groups; (1) a group where target words were taught with the use of translation equivalents, (2) a group taught with L2-only-definitions and (3) a control group who received no special treatment. Comparing the participants' performance in pre-, immediate post- and delayed post-tests showed that the two experimental groups outperformed the control group, reflecting the benefit of the treatment. The results also showed greater vocabulary gains in terms of long-term retrieval for L1 use, but did not show consistent patterns for the special benefit of L1 in terms of specific word types. The results are interpreted in light of the existing literature and relevant bilingual lexicon models. Pedagogical implications and suggested research directions are also proposed.
\end{abstract}

Keywords: vocabulary learning, second language learning, first language, word type, bilingual lexicon

\section{Introduction}

It is widely acknowledged that effective vocabulary knowledge is central to second language (L2) learning as vocabulary is of critical importance to communicative competence and successful second language use (e.g., Nation, 2001; Schmitt, 2000; Zimmerman, 1997). It is thus a major responsibility for second language acquisition (SLA) researchers to explore effective pedagogical methods to help L2 learners master vocabulary in the target language, particularly that L2 vocabulary is considered problematic (e.g., Oxford, 1990; Meara, 1980) due to its huge size, its open-ended nature, lack of relevant governing rules and the multitude of meanings of lexical items. In this regard, two approaches to vocabulary learning are generally contrasted; incidental learning and intentional learning (Tian \& Macaro, 2012). In incidental learning, on the one hand, the learner's attention is predominantly focused on the message the text conveys rather than the forms through which this message is communicated. However, the learner may still learn new lexical items that are especially noticeable. Intentional learning, on the other hand, draws learners' attention to the form-meaning relationships in texts with the aim of enhancing vocabulary learning. The present paper falls under the domain of intentional learning as it addresses the explicit instruction of L2 vocabulary using the learners' native versus target language.

In different parts of the world, L2 classrooms comprise students speaking the same native language as their bilingual instructor. In this case, an on-going debate often emerges whether the L2 should be used (1) as the only valid medium of instruction, (2) as the dominant or preferred instruction medium or (3) in combined use with the L1 with each having its own value (Zhao \& Macaro, 2016). Intralingual teaching strategies include the use of definitions, paraphrases, circumlocution, exposition, contextualization and sense relations while interlingual strategies mainly rely on the use of translation equivalents. The sole use of L2 as the medium of instruction is largely dependent on theoretical grounds as input and interaction research (e.g., Long, 1996; Swain, 1995; Krashen, 1985) support the potential acquisition of L2 morphosyntax and vocabulary through modified input, 
negotiation of meaning and forced output. Besides, the sole L2 use increases the amount of L2 exposure and is assumed to support the development of L2 learners' inferencing skills. Hence, early and strong versions of the communicative teaching approach advocate the sole use of the target language (Ramachandran \& Abdul Rahim, 2004). Likewise, policy makers worldwide have increasingly imposed a L2-only approach even in contexts where the target language is a foreign language and learners thus receive minimal L2 exposure (Lee \& Macaro, 2013).

Recently, however, the use of L1 has gained support on both theoretical and practical grounds. Theoretically, Kroll \& Stewart's (1994) Revised Hierarchical Model (RHM) proposes that L2 lexemes access relevant concepts through L1 mediation at early stages of L2 learning due to the strong links between L1 lexemes and the conceptual store. As L2 proficiency increases, links between L2 lexemes and their concepts strengthen reducing the need for L1 mediation in L2 lexical access. Hence, the use of L1 with L2 beginning learners may be beneficial. Likewise, De Groot's (1993; 1992) Distributed Feature Model (DFM) assumes that a bilingual's languages share the same conceptual representations with varying extents depending on the activation levels of common features of L1 and L2 lexemes. Practically, Zhao \& Macaro (2016) highlight that L2-only explanations may be too difficult to understand and may be too cognitively demanding for learners to memorize the meaning of new words. Besides, teachers and learners may have limited time to adequately interact and negotiate meaning in the classroom to sufficiently support vocabulary learning. In addition, Ghobadi \& Ghasemi (2015) point out the inevitable L1 use with beginning L2 learners for varied purposes including the classroom-management functions. They also refer to the important role of L1 from an identity perspective as L2 learners generally feel more comfortable with L2 use if proper room is allowed for L1 use.

With the current agreement on the benefits of L1 use, SLA researchers' focus has shifted to the factors defining the "optimal use" of the L1 (Macaro, 2009, p. 38, in Turnbull \& Dailey-O'Cain, 2009). Few studies have recently adopted this direction, such as Lee \& Macaro (2012) on the age factor and Zhao \& Macaro (2016) on word type (see the literature review for further details). The current study follows this new direction as it examines the effect of word type (defined in terms of concrete versus abstract nouns and action versus state verbs) on the L1 use in the English as a foreign language (EFL) learning context. The study aims to explore if the L1 use is influenced by differences in word types. In the study's specific terms, is the L1 use more effective for the learning of concrete nouns as compared to abstract nouns or to action verbs as compared to state verbs? In other words, should the L2 teacher consider word type while selecting the relevant medium of instruction, whether L1 or L2?

\section{Literature Review}

The literature on the L1 use in the L2 classroom has targeted various L2s (e.g., Spanish by Nakatsukasa \& Loewen (2015); French by Hennebry, Rogers, Macaro, \& Murphy (2013); German by Kaushik, 2013) and different directions, such as grammar instruction (e.g., Ghaiyoomian \& Zarei, 2015; Aslikhosh, 2014; Damra \& Al Qudah, 2012), writing instruction (e.g., Berming, 2016; Kim and Yoon 2014), students' perceptions (e.g., Debreli \& Oyman, 2016; Al Sharaeai, 2012; Nazary, 2008) and teachers' perceptions (e.g., Karimian \& Mohammadi (2015); Ahmed (2015); Mohebbi \& Alavi, 2014). The present literature review focuses on studies on EFL vocabulary instruction for relevance with the current study. The review comprises two categories of studies; (1) those providing support for the L1 use and (2) those exploring relevant determinants for the effective L1 use.

\subsection{Support for the L1 use in L2 Vocabulary Instruction}

Empirical studies providing pedagogical support for the benefit of the L1 use in L2 vocabulary instruction come from varied environments. For instance, Ramachandran \& Abdul Rahim (2004) investigated the effectiveness of the translation method as compared to a non-translation method on the recall and retention of L2 vocabulary learning for elementary EFL Malay learners. A total of 60 secondary school students in Penang, Malaysia, with an average age of 16, participated in the study. The participants were introduced to 20 new English words as part of their reading sessions. The 20 items were taught 5 words per session with a total duration of 4 reading sessions over 4 weeks. The experimental group $(\mathrm{n}=30)$ were introduced to the target words through the translation method while a non-translation method was employed with the control group $(n=30)$. The target vocabulary was taught within the reading texts to conform to the curriculum requirement to teach lexical items within context, but the context was appropriately simplified and the occurrence of items emphasized. At the end of every session, an immediate post-test required the participants to provide the meaning of the taught words in Malay or English. A month after the end of the treatment, during which words taught earlier were regularly recycled, a delayed post-test with the same format was also administered. The participants' scores on both tests 
supported the positive effect of the translation method on the recall and retention of EFL vocabulary for elementary Malay learners.

Another relevant study is Liu (2008) which targeted Chinese EFL learners. The participants were all Chinese-speaking undergraduate students of non-English majors with similar English proficiency. Divided into an experimental group $(\mathrm{n}=55)$ and a control group $(\mathrm{n}=57)$, all participants completed a vocabulary test composed of 60 English words/ expressions that were estimated to be new to the undergraduates. The participants' task was to mark the English words they know and write their meaning in Chinese. Then, the participants read 2 English essays that contained all the 60 words and the teachers provided a brief explanation in English. In the control group, the teacher intentionally explained the 60 words in English and asked the participants to underline the words to enhance their attention. In the experimental group, however, the teacher explained the target words in both English and Chinese while the participants underlined the words in the essays and wrote down their Chinese meanings. Three weeks after this activity, the two groups were given a second vocabulary test consisting of 60 sentences, each including one target word. The participants were asked to translate the sentences into Chinese. Although the results of the first vocabulary test led to comparable scores, the results of the second test came significantly in favor of the experimental group. The researcher thus discouraged the avoidance of the Chinese language in EFL vocabulary classes, and rather urged teachers to combine English explanations with Chinese translation as a quick and efficient means for initial word learning.

Likewise, Tian \& Macaro (2012) targeted Chinese EFL learners, but within listening comprehension sessions. A total of 80 freshmen enrolled in English language classes as part of their university program participated in the study. The participants were 19 years old in average and belonged to the middle tier of English proficiency based on the national university entrance exam. Over a period of 6 weeks, the participants were taught new vocabulary within listening comprehension sessions either through focus-on-form or incidentally. The focus-on-form groups fell into two conditions; (1) code-switching between English and Chinese or (2) English-only explanation. Examining the participants' performance in pre-, post- and delayed post-tests of the new lexical items showed that the focus-on-form approach leads to better vocabulary learning than mere incidental exposure and that code-switching may be superior to the L2-only explanations regardless of the participants' proficiency level.

The use of Persian as a L1 in EFL classrooms was also investigated. For example, Pakzadian (2012) investigated the effect of the use of L1 translation equivalents versus L2 paraphrases on the reading comprehension and vocabulary learning of Iranian EFL learners. The participants were all Persian-speaking studying English at a private language school in Isfhan, Iran. Their ages ranged between 14 and 20 and their proficiency level was assessed at an intermediate level. After ensuring the homogeneity of the participants and checking the participants' knowledge of the target words through piloting, reading passages containing the new target words $(\mathrm{n}=50)$ were provided to the participants to read and answer the following multiple choice questions. One group $(\mathrm{n}=27)$ of the participants received the reading texts without any supplementation while a second group $(\mathrm{n}=25)$ had English definitions next to the new words and a third group $(n=30)$ had Persian translation equivalents next to the target words. One week after the comprehension test, the participants were given a vocabulary test in the matching format including the same target words. The overall findings revealed no difference among the three groups with respect to reading comprehension whereas the third group which received Persian translations of target words outperformed the two other groups in the subsequent vocabulary test. The researcher thus concluded that the mother tongue played a facilitative role in learning English for Persian speakers.

Similarly, the effect of the use of Arabic as a native language in EFL classrooms was examined by Khan (2016). The participants were all post-secondary Saudi students at the English language program preparing them for college education at a Saudi university. The participants $(n=40)$ aged 18 in average and were assessed to be of the same proficiency level as per institutional language proficiency tests. The participants were divided into two groups, each composed of 20 participants. The two groups were assigned to read a number of texts, which was followed by a post-reading vocabulary test of 30 words that were pre-determined in the assigned texts for the purpose of the study. The scores of the tests were similar for the two groups. This was followed by instructional intervention as one group of participants was provided with explanation of the set vocabulary in English while the second group received vocabulary instruction in the form of Arabic translation equivalents. When the 30 -word vocabulary test was repeated, the group provided with translation equivalents in the intervention phase scored higher than the other group, which led the researcher to recommend the use of translation equivalents to teach vocabulary for Saudi EFL learners.

The current section has surveyed sample empirical studies providing support for the L1 use for L2 vocabulary instruction. It is worth noting though that the survey is not meant to be exhaustive as various other studies have led to similar conclusions (e.g., Camó \& Ballester, 2015; Fatemi \& Barani, 2014; Khansir \& Tabande, 2014; 
Hayati \& Shahriari, 2010; Latsanyphone \& Bouangeune, 2009).

\subsection{Determinants of Effective L1 Use}

The strong agreement in favor of the L1 use in L2 vocabulary learning has recently called for research into the relevant determinants influencing the effectiveness of this use. In other words, under what conditions is the L1 recommended for use in L2 vocabulary classes? Few studies have so far attempted to address this question. A relevant study examining the influence of the age factor is Lee \& Macaro (2013). This study examined the effect of the use of the native language through code-switching as compared to the use of the L2-only explanation on the acquisition and retention of new lexical items for two age groups. The two groups (i.e., 443 elementary school children versus 286 tertiary freshmen) were native speakers of Korean and recruited from schools/ colleges in the cities of Seoul and Incheon, South Korea. Within each group, the school type, proficiency level, teaching materials and target lexical items were similar. The socioeconomic status, teaching approach and instructional procedure were also similar across the two groups. Each group was further sub-divided into two groups; one taught by a bilingual teacher allowing limited code-switching into Korean for the teaching of new lexical items, and another group taught by a native speaker of English who used English-only explanations. Based on pre-, post- and delayed-post receptive vocabulary tests, the study showed that both age groups benefited more from code-switching into the participants' L1 than L2-only definitions/ paraphrases although the benefit was much clearer for the younger participants. The researchers interpreted the benefit in terms of a combination of age-related learning expertise together with proficiency levels, and thus suggested L1 may have some beneficial effects on L2 vocabulary learning, particularly for the young inexperienced learners.

Another relevant study is Lotto \& De Groot (1998) which compared the influence of the use of L1 translation equivalents versus the use of the referents' pictures on the learning of L2 lexical items that varied in word type. The 56 Dutch-speaking participants who were unfamiliar with Italian were divided into 4 groups $(\mathrm{n}=14$ each). Two groups were taught 80 Italian words via Dutch translation equivalents while the other two groups practiced the same words with pictures of referents. After 3 learning trials, the 4 groups performed a recall test with 2 groups tested with congruent cues (e.g., learned words in pictures and tested with picture cues) whereas the other two groups completed the task with incongruent cues (e.g., learned words in pictures and tested with translation equivalents). The test was performed one more time after 3 additional learning trials of the target words. Examining the participants' retrieval times and recall scores revealed that learning via translation equivalents led to better performance than picture learning with performance generally superior in congruent than incongruent conditions. As for word type, clear cognate and frequency effects were displayed regardless of the word learning methods.

Similarly interested in the word type factor, Zhao \& Macaro (2016) investigated whether teachers' L1 use or L2-only explanations works better as a medium of instruction for the learning of concrete and abstract English words among adult Chinese-speaking EFL learners. To this end, a total of 148 university students who are non-English majors participated in a study with a quasi-experimental design. The participants comprised three groups; one where English words were taught with the use of the participants' L1 ( $n=50)$, a second where English words were taught using L2-only explanations $(\mathrm{n}=50)$ and a third which served as a comparison group and received no treatment related to vocabulary learning. Using a $3 \mathrm{X} 3$ mixed ANOVA, the three groups were compared over 3 time points with respect to the instructional type (i.e., L1 vs. L2 vs. comparison group) and time of tests (i.e., pre-test, immediate post-test and delayed post-test). The results revealed greater vocabulary gains in immediate and delayed tests for L1 use over L2-only explanations. These results were interpreted in terms of the easier processing of lexical information provided in L1 through the direct lexical route and the potential blurred semantic boundaries between target words and their semantically associated words.

The current study shares the same interest of Lotto \& De Groot (1998) and Zhao \& Macaro (2016) in the word type factor, which is obviously under-researched in the context of the optimal use of the first language in L2 vocabulary learning. Extending Zhao \& Macaro's (2016) research, the present study compares the benefits of the L1 use for concrete versus abstract nouns and for action versus state verbs in the L2. In addition to extending the Zhao \& Macaro's (2016) definition of word type to cover action versus state verbs, the current study also addresses a new population; i.e., Arabic-speaking EFL learners. It is intriguing to see if similar findings would emerge as Zhao \& Macaro (2016) within the new learning context and for the additional word type.

\section{Research Question}

The present study addresses the research question: What works better for the learning of L2 words; teachers' L1 use or L2-only explanations? The question targets 4 word types:

1) Concrete nouns 
2) Abstract nouns

3) Action verbs

4) State verbs

\section{Methodology}

\subsection{Participants}

A total of 130 female Arab EFL learners participated in the current study. The participants, whose first language is Arabic and average age is 18 , were recruited from a private Saudi university which allows admission by both Saudi and non-Saudi students and where the English language is the medium of instruction for all majors. In order to ensure the students' readiness for university education in English, all students sit for an English language placement test upon admission. Only those at the intermediate level or with equivalent scores to 5.5 on IELTS are allowed to join their selected majors. Applicants with lower scores are classified into three levels of beginners, elementary and pre-intermediate and enroll in a Preparatory Year Program (PYP) which qualifies them for the language requirements of university education. The PYP students receive training on all English language skills through an intensive program providing 20 contact hours per week. The participants in the current study were recruited from six intact classes of the elementary level, where participants were not randomized for practical educational considerations.

\subsection{Materials}

The first step in preparing the study materials was to select the target stimuli. To this end, a list of 160 words, comprising equal numbers of concrete nouns, abstract nouns, action verbs and state verbs, was prepared by the researchers based on their experience as previous/current PYP instructors. The list included a variety of familiar and unfamiliar words to the PYP students as per the researchers' discretion. The list was then disseminated to 15 experienced PYP instructors to assess the PYP students' knowledge of these words on a 5-point Likart scale. The highest end of the scale (i.e., 5) entailed that the students' knowledge of the target words is excellent while the lowest end (i.e., 1) indicated that the students' knowledge of the target words is poor. Based on the instructors' accumulative judgment, a total of 24 words unfamiliar to the participants were finally selected for the study purposes. The final list included 6 words of each target word type. It is worth noting that the researchers decided to rely on subjective frequency assessment rather than standard word frequency measures because the participants may know words of lower frequency from their previous or current school curricula.

The choice of the target word types in the current study was empirically supported. Regarding the selection of concrete versus abstract nouns, they entail different processing mechanisms (e.g., Barsalou, 1999), vary in the degree of imageability and availability of contextual information (e.g., Altarriba, Bauer, \& Benventuo, 1999), may be acquired differently (e.g., Van Hell \& Mahn, 1997) and display varied mental association patterns for bilinguals (e.g., Author, 2017). Besides, De Groot's (1993; 1992) DFM proposes that concrete words are processed differently than abstract words for bilinguals since the concepts that concrete words represent are assumed to be more similar across languages. As for action versus state verbs, the distinction is referred to in the literature though to a much less extent than the concreteness effect. The processing of verbs is influenced by the degree to which a verb is linked to its perceptual referent (e.g., Marian \& Kaushanskaya, 2007). Hence, it has been found that action and state verbs are processed differently in bilingual contexts (e.g., Segalowitz \& De Almeida, 1992) and develop unparalleled mental associations in the L2 lexicon (e.g., Author, 2017).

In addition, a vocabulary test was devised to assess the participants' knowledge of the target stimuli. The test was implemented in a pre, immediate post and delayed-post format. The test was an adaptation of Paribakht and Wesche, 1993's Vocabulary Knowledge Test (VKT) in Table (1). The test in the current study (see Appendix A) maintained items I and II of the VKT format to differentiate totally unfamiliar words from familiar words with unclear meanings. The researchers, however, modified items III and IV to distinguish the words with vague than clear meanings for the participants. In Item III, the participants were only asked to classify words into categories while the participants had to write the meaning of the target words in Arabic or English in Item IV. Item V of the VKT format, which required the participants to place target words in sentences, was deleted as it was not deemed necessary for the study purpose. 
Table 1. VKT test format (Paribakht \& Wesche, 1993)

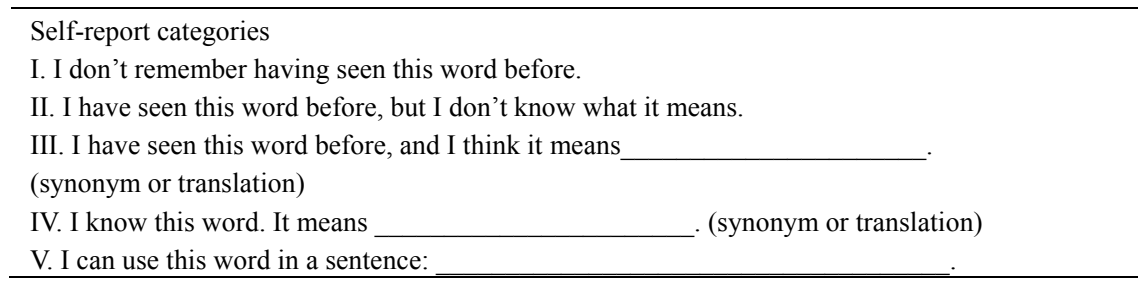

\subsection{Procedure}

The study was implemented over 6 weeks in the months of November and December 2016. The six classes participating in the study were divided into two experimental groups and a control group. One experimental group ( $\mathrm{n}=45)$ was taught the stimuli using English-only definitions, the other experimental group $(\mathrm{n}=40)$ was introduced to the words using Arabic translation and the control group $(\mathrm{n}=45)$ did not receive any special treatment. As Table (2) shows the first week was assigned for a pre-test for all groups, weeks 2-5 represented the treatment period for the experimental groups and the immediate post-tests for all groups and week 6 was kept for the delayed post-test. The pre and delayed post-tests included all 24 stimuli while each of the treatment weeks was assigned for one word type for instruction and immediate post-tests. To support L2 learning, the target words were taught in 4 themes; objects (=concrete nouns), personality traits (=abstract nouns), actions (=action verbs) and feelings (=state verbs) (see Appendix B for the target stimuli).

Table 2. Study design

\begin{tabular}{|c|c|c|c|c|c|c|}
\hline Week 1 & Week 2 & Week 3 & Week 4 & & Week 5 & Week 6 \\
\hline \multirow[t]{4}{*}{ Pre-Test } & Concrete nouns & Abstract nouns & $\underline{\text { Action verbs }}$ & & $\underline{\text { State verbs }}$ & Delayed \\
\hline & Treatment + Immediate & Treatment + & Treatment & + & Treatment + Immediate & Post-Test \\
\hline & Post-Test & Immediate & Immediate & & Post-Test & \\
\hline & & Post-Test & Post-Test & & & \\
\hline
\end{tabular}

Permission was sought from the university's concerned authorities and the class instructors to implement the study in the six selected classes. The class instructors explained the research purpose to their students who welcomed participating in the study for additional vocabulary practice. The students who did not consent were allowed to leave the classroom during the study slots. The study was implemented by the 3 researchers in addition to a volunteering colleague. The 4 instructors, whose ages ranged between 30 and 40, had been teaching English language for Arab EFL learners for 10-20 years, are themselves native speakers of Arabic and generally adhere to communicative teaching methods. All the instructors hold post-graduate degrees in English language studies.

The lesson plans and teaching materials were prepared by one of the researchers who is the most experienced in PYP instruction. The plans and materials were unified to ensure consistency of implementation across classes and among instructors. The lesson plans for the experimental groups included a brief lead-in to the lesson theme, the instructor reading every word out loud and explaining the word using the L1 or L2-only definition while displaying the explanation on the screen, the students repeating every word twice, the instructor reading a relevant example sentence displayed on the screen and finally the students supplying two additional relevant sentences. After the six words were practiced, the immediate post-test was administered. The target vocabulary was thus practiced in separate vocabulary sessions not linked to other language skills, such as reading or listening, but the words were still introduced thematically. As for the control group, it did not receive any treatment related to vocabulary learning.

After the implementation of the study, the tests were marked by the researchers. Scores were assigned to reflect the participants' depth of vocabulary knowledge. Marking a word as "never seen before" (test item I) led to score "zero" while marking a word as "seen before but not clear about its meaning" (test item II) led to score "one." Being able to assign a correct category to the word (test item III) resulted in score "two" whereas being able to explain the target word in English or Arabic (test item IV) was scored at "three." Giving wrong answers in items III or IV was scored at "one" similar to test item II. 


\section{Results}

In order to answer the research question "What works better for the learning of L2 words; teachers' L1 use or L2-only explanations?" the performance of the experimental and control groups on the pre-, immediate post- and delayed post-tests was compared with ANOVA which allowed the examination of instructional type (i.e., L1 use, L2-only explanation or no explicit instruction) as a between-subject factor and time of test (pre-, immediate postand delayed post) as a within subject factor. For further accuracy, the ANOVA results were supplemented with Bonferroni-corrected post hoc pairwise comparisons. The findings are reported in this section categorized by word type.

\subsection{Concrete Nouns}

Table 3 shows the statistical analysis results for concrete nouns. Comparisons of instructional type reflect significantly better performance for the experimental groups over the control group in the immediate post-tests, which was maintained in the delayed post-tests. No significant statistical difference was noted though between the two experimental groups in either of the post-tests. As for test time, the L2-only-definitions group demonstrated better performance in the immediate post-test than the pre-test. However, this improvement was not maintained in the delayed post-test. The performance of the L1-use group, on the contrary, was significantly better at both post-tests than the pre-test although it was higher for the immediate post-test.

Table 3. Statistical comparisons for concrete nouns

\begin{tabular}{|c|c|c|c|c|c|c|c|c|c|c|c|c|}
\hline \multicolumn{7}{|c|}{ Comparison between groups } & \multicolumn{6}{|c|}{ Comparison between time points of test } \\
\hline \multirow{7}{*}{ Pretest } & & & MD & SE & Sig. & $\mathrm{Eta}^{2}$ & & & MD & SE & Sig. & $\mathrm{Eta}^{2}$ \\
\hline & $\mathrm{L} 1$ & vs. & -.38333 & .15171 & .038 & .062 & L1 & Pre vs. post & -2.00000 & .26856 & .000 & .322 \\
\hline & $\mathrm{L} 2$ & & & & & & & & & & & \\
\hline & $\mathrm{L} 1$ & vs. & -.38333 & .15171 & .038 & & & Pre vs. delayed post & -1.07500 & .26856 & .000 & \\
\hline & CG & & & & & & & & & & & \\
\hline & $\mathrm{L} 2$ & vs. & .00000 & .14718 & 1.000 & & & Post vs. delayed & .92500 & .26856 & .002 & \\
\hline & CG & & & & & & & post & & & & \\
\hline \multirow[t]{6}{*}{ Post-test } & $\mathrm{L} 1$ & vs. & .23889 & .30513 & 1.000 & .172 & $\mathrm{~L} 2$ & Pre vs. post & -1.37778 & .24730 & .000 & .204 \\
\hline & $\mathrm{L} 2$ & & & & & & & & & & & \\
\hline & $\mathrm{L} 1$ & vs. & 1.43889 & .30513 & .000 & & & Pre vs. delayed post & -.33333 & .24730 & .540 & \\
\hline & CG & & & & & & & & & & & \\
\hline & $\mathrm{L} 2$ & vs. & 1.20000 & .29602 & .000 & & & Post vs. delayed & 1.04444 & .24730 & .000 & \\
\hline & CG & & & & & & & post & & & & \\
\hline \multirow{6}{*}{$\begin{array}{l}\text { Delayed } \\
\text { post-test }\end{array}$} & $\mathrm{L} 1$ & vs. & .35833 & .21318 & .286 & .253 & $\mathrm{C}$ & Pre vs. post & -.17778 & .16826 & .878 & .167 \\
\hline & L2 & & & & & & G & & & & & \\
\hline & $\mathrm{L} 1$ & vs. & 1.33611 & .21318 & .000 & & & Pre vs. delayed post & .64444 & .16826 & .001 & \\
\hline & CG & & & & & & & & & & & \\
\hline & $\mathrm{L} 2$ & vs. & .97778 & .20681 & .000 & & & Post vs. delayed & .82222 & .16826 & .000 & \\
\hline & CG & & & & & & & post & & & & \\
\hline
\end{tabular}

\subsection{Abstract Nouns}

Table 4 shows the statistical analysis results for abstract nouns. In terms of instructional type, both experimental groups outperformed the control group in the two post-tests. The L1-use group also outperformed the L2-only-definitions group but only in the delayed post-test. As for test time, the performance of the L2-only-definitions group was significantly better at the immediate post-test than the pre-test whereas the L1-use group reflected significantly better performance at both the immediate and delayed post-tests. 
Table 4. Statistical comparisons for abstract nouns

\begin{tabular}{|c|c|c|c|c|c|c|c|c|c|c|c|c|}
\hline \multicolumn{7}{|c|}{ Comparison between groups } & \multicolumn{6}{|c|}{ Comparison between time points of test } \\
\hline & & & $\mathrm{MD}$ & SE & Sig. & $\mathrm{Eta}^{2}$ & & & $\mathrm{MD}$ & SE & Sig. & $\mathrm{Eta}^{2}$ \\
\hline \multirow[t]{6}{*}{ Pretest } & $\mathrm{L} 1$ & vs. & -.37500 & .16432 & .072 & .069 & $\mathrm{~L} 1$ & Pre vs. post & -1.70000 & .26677 & .000 & .263 \\
\hline & $\mathrm{L} 2$ & & & & & & & & & & & \\
\hline & $\mathrm{L} 1$ & vs. & -.48611 & .16432 & .011 & & & Pre vs. delayed & -1.10000 & .26677 & .000 & \\
\hline & $\mathrm{CG}$ & & & & & & & post & & & & \\
\hline & $\mathrm{L} 2$ & vs. & -.11111 & .15942 & 1.000 & & & Post vs. delayed & .60000 & .26677 & .079 & \\
\hline & $\mathrm{CG}$ & & & & & & & post & & & & \\
\hline \multirow[t]{6}{*}{ Post-test } & L1 & vs. & .14722 & .26951 & 1.000 & .175 & L2 & Pre vs. post & -1.17778 & .20440 & .000 & .229 \\
\hline & L2 & & & & & & & & & & & \\
\hline & $\mathrm{L} 1$ & vs. & 1.25833 & .26951 & .000 & & & Pre vs. delayed & -.15556 & .20440 & 1.00 & \\
\hline & $\mathrm{CG}$ & & & & & & & post & & & 0 & \\
\hline & $\mathrm{L} 2$ & vs. & 1.11111 & .26147 & .000 & & & Post vs. delayed & 1.02222 & .20440 & .000 & \\
\hline & $\mathrm{CG}$ & & & & & & & post & & & & \\
\hline \multirow{6}{*}{$\begin{array}{l}\text { Delayed } \\
\text { post-test }\end{array}$} & L1 & vs. & .56944 & .21324 & .026 & .255 & $\mathrm{C}$ & Pre vs. post & .04444 & .18317 & 1.00 & .147 \\
\hline & $\mathrm{L} 2$ & & & & & & G & & & & 0 & \\
\hline & & vs. & 1.39167 & .21324 & .000 & & & Pre vs. delayed & .77778 & .18317 & .000 & \\
\hline & CG & & & & & & & post & & & & \\
\hline & & vs. & .82222 & .20687 & .000 & & & Post vs. delayed & .73333 & .18317 & .000 & \\
\hline & CG & & & & & & & post & & & & \\
\hline
\end{tabular}

\subsection{Action Verbs}

Table 5 shows the statistical analysis results for action verbs. Regarding the instructional type, the performance of the L1-use group improved greatly in the immediate post-test that it outperformed the two other groups although it had significantly lower scores in the pre-test. As for the delayed post-test, the two experimental groups outperformed the control group with the L1-use group maintaining its advantage over the L2-only-definitions group. Comparisons in terms of test time showed no improvement in the performance of the L2-only-definitions group over the three tests. The L1-use group displayed different results as the group's performance was significantly better at the two post-tests than the pre-test with no statistical difference between the immediate and delayed post-tests.

Table 5. Statistical comparisons for action verbs

\begin{tabular}{|c|c|c|c|c|c|c|c|c|c|c|c|c|}
\hline \multicolumn{7}{|c|}{ Comparison between groups } & \multicolumn{6}{|c|}{ Comparison between time points of test } \\
\hline & & & MD & SE & Sig. & $\mathrm{Eta}^{2}$ & & & MD & SE & Sig. & $\mathrm{Eta}^{2}$ \\
\hline \multirow[t]{4}{*}{ Pretest } & L1 & vs. & -.51389 & .19037 & .024 & .070 & L1 & Pre vs. post & -1.42500 & .30813 & .000 & .169 \\
\hline & L2 & & & & & & & & & & & \\
\hline & $\begin{array}{l}\text { L1 } \\
\text { CG }\end{array}$ & vs. & -.51389 & .19037 & .024 & & & $\begin{array}{l}\text { Pre vs. delayed } \\
\text { post }\end{array}$ & -1.12500 & .30813 & .001 & \\
\hline & $\begin{array}{l}\mathrm{L} 2 \\
\mathrm{CG}\end{array}$ & vs. & .00000 & .18468 & 1.000 & & & $\begin{array}{l}\text { Post vs. delayed } \\
\text { post }\end{array}$ & .30000 & .30813 & .997 & \\
\hline \multirow[t]{3}{*}{ Post-test } & $\begin{array}{l}\mathrm{L} 1 \\
\mathrm{~L} 2\end{array}$ & vs. & .51111 & .33401 & .385 & .075 & L2 & Pre vs. post & -.40000 & .26008 & .379 & .025 \\
\hline & $\begin{array}{l}\mathrm{L} 1 \\
\mathrm{CG}\end{array}$ & vs. & 1.06667 & .33401 & .005 & & & $\begin{array}{l}\text { Pre vs. delayed } \\
\text { post }\end{array}$ & .02222 & .26008 & $\begin{array}{l}1.00 \\
0\end{array}$ & \\
\hline & $\begin{array}{l}\mathrm{L} 2 \\
\mathrm{CG}\end{array}$ & vs. & .55556 & .32404 & .267 & & & $\begin{array}{l}\text { Post vs. delayed } \\
\text { post }\end{array}$ & .42222 & .26008 & .321 & \\
\hline \multirow{3}{*}{$\begin{array}{l}\text { Delayed } \\
\text { post-test }\end{array}$} & L1 & vs. & .63333 & .23139 & .021 & .269 & $\mathrm{C}$ & Pre vs. post & .15556 & .19970 & 1.00 & .166 \\
\hline & $\begin{array}{l}\text { L2 } \\
\text { L1 } \\
\text { CG }\end{array}$ & vs. & 1.56667 & .23139 & .000 & & G & $\begin{array}{l}\text { Pre vs. delayed } \\
\text { post }\end{array}$ & .95556 & .19970 & $\begin{array}{l}0 \\
.000\end{array}$ & \\
\hline & $\begin{array}{l}\mathrm{L} 2 \\
\mathrm{CG}\end{array}$ & vs. & .93333 & .22449 & .000 & & & $\begin{array}{l}\text { Post vs. delayed } \\
\text { post }\end{array}$ & .80000 & .19970 & .000 & \\
\hline
\end{tabular}

\subsection{State Verbs}

Table 6 shows the statistical analysis results for state verbs. The instructional type analysis shows that the two experimental groups outperformed the control group in the immediate and delayed post-tests with the L1-use 
group maintaining a significant advantage over the L2-only-defnitions group. The test time analysis reflected different patterns for the two experimental groups. The L2-only-definitions group scored significantly higher in the immediate post-test than the pre-test, but lost this advantage in the delayed post-test. The L1-use group showed similar improvement in the immediate post-test than the pre-test. However, the L1-use group managed to maintain this advantage in the delayed post-test despite the lower scores in the delayed than the immediate post-tests.

Table 6. Statistical comparisons for state verbs

\begin{tabular}{|c|c|c|c|c|c|c|c|c|c|c|c|c|}
\hline \multicolumn{7}{|c|}{ Comparison between groups } & \multicolumn{6}{|c|}{ Comparison between time points of test } \\
\hline & & & MD & SE & Sig. & $\mathrm{Eta}^{2}$ & & & MD & SE & Sig. & $\mathrm{Eta}^{2}$ \\
\hline \multirow[t]{6}{*}{ Pretest } & $\mathrm{L} 1$ & vs. & -.21111 & .16205 & .585 & .024 & L1 & Pre vs. post & -2.22500 & .25882 & .000 & .388 \\
\hline & $\mathrm{L} 2$ & & & & & & & & & & & \\
\hline & $\mathrm{L} 1$ & vs. & -.27778 & .16205 & .267 & & & Pre vs. delayed & -1.02500 & .25882 & .000 & \\
\hline & CG & & & & & & & post & & & & \\
\hline & $\mathrm{L} 2$ & vs. & .06667 & .15721 & 1.000 & & & Post vs. delayed & 1.20000 & .25882 & .000 & \\
\hline & CG & & & & & & & post & & & & \\
\hline \multirow[t]{6}{*}{ Post-test } & $\mathrm{L} 1$ & vs. & 1.16944 & .28027 & .000 & .307 & L2 & Pre vs. post & -.84444 & .22500 & .001 & .103 \\
\hline & $\mathrm{L} 2$ & & & & & & & & & & & \\
\hline & $\mathrm{L} 1$ & vs. & 2.10278 & .28027 & .000 & & & Pre vs. delayed & -.22222 & .22500 & .975 & \\
\hline & $\mathrm{CG}$ & & & & & & & post & & & & \\
\hline & $\mathrm{L} 2$ & vs. & .93333 & .27191 & .002 & & & Post vs. delayed & .62222 & .22500 & .019 & \\
\hline & $\mathrm{CG}$ & & & & & & & post & & & & \\
\hline \multirow{6}{*}{$\begin{array}{l}\text { Delayed } \\
\text { post-test }\end{array}$} & $\mathrm{L} 1$ & vs. & .59167 & .20948 & .017 & .267 & $\mathrm{C}$ & Pre vs. post & .15556 & .17676 & 1.00 & .106 \\
\hline & L2 & & & & & & G & & & & 0 & \\
\hline & $\mathrm{L} 1$ & vs. & 1.41389 & .20948 & .000 & & & Pre vs. delayed & .66667 & .17676 & .001 & \\
\hline & $\mathrm{CG}$ & & & & & & & post & & & & \\
\hline & & vs. & .82222 & .20323 & .000 & & & Post vs. delayed & .51111 & .17676 & .013 & \\
\hline & $\mathrm{CG}$ & & & & & & & post & & & & \\
\hline
\end{tabular}

\section{Discussion}

The results of the current study must be examined from two perspectives. Regarding the instruction type, the two experimental groups outperformed the control group across all word types in the immediate post-test although the difference did not reach statistical significance for the L2-only-definitions group in action verbs. No statistical difference was noted between the two experimental groups for concrete nouns, abstract nouns and action verbs. Only in the condition of state verbs, the L1-use group outperformed the L2-only-definitions group. It thus seems that the experimental treatment, whether with the use of L1 or L2, proved beneficial for the participants as expected. As for test time, the performance of the L2-only-definitions group significantly improved in the immediate post test than the pre-test for concrete nouns, abstract nouns and state verbs. However, the group failed to maintain this improvement in the delayed post-test which showed no statistical difference than the pre-test. The action verbs represented an exception to this pattern as no statistical differences were noted for test time. It thus generally seems that the L2-only- definitions supports short-term rather than long-term retrieval. The L1-use group demonstrated stronger vocabulary gains as the group performance significantly improved in the immediate and delayed post-tests than the pre-test across word types with an advantage for the immediate post-test for concrete nouns and state verbs. This finding comes in line with earlier studies in support of the benefits of the L1 use in L2 vocabulary learning (e.g., Khan, 2016; Pakzadian, 2012; Tian \& Macaro, 2012; Liu, 2008; Ramachandran \& Abdul Rahim, 2004).

The findings of the current study are closely linked to models of the bilingual mental lexicon. As mentioned earlier, Kroll \& Stewart's (1994) RHM predicts greater vocabulary gains for the L1-use group as it assumes that L2 words access their concepts through L1 mediation at early stages of L2 learning. Since the study participants are classified at an elementary level, the RHM provides a plausible explanation for the special L1 benefits. Similarly, De Groot's (1993; 1992) DFM predicts stronger benefits for the L1-use group based on its assumption that a bilingual's languages share the same conceptual representations. However, the findings of the current study only partially support the DFM's prediction for a facilitated processing of concrete words due to similarity of relevant concepts across languages. The benefit of L1 use was better maintained at the delayed post-test for action rather than state verbs. However, the pattern was unexpectedly reversed for nouns where the L1 use led to more sustained gains at the delayed post-tests for abstract than concrete nouns. This might be interpreted in 
terms of the low proficiency level of the study participants which may have not allowed for the full emergence of the concreteness effect, or it could be related to the specific choice of stimuli as learning personality traits could have proved of special interest for the participants than learning the names of objects they rarely use, such as "hatchet" and "easel".

Regarding previous studies on the determinants for effective L1 use, it is intriguing to compare the findings of the current study with earlier relevant results. In Lee \& Macaro (2013), benefits for the L1 use were noted for both age groups, but greater gains were found for the younger and less experienced learners. The participants in the current study can be classified as less experienced learners of English as they only reached an elementary level in the university admission tests. As for Zhao \& Macaro's (2016) study, which is of extreme relevance to the present study, it showed that the L1-use group outperformed the other two groups with the L2-only-explanation group outperforming the control group. The present study showed similar results except that the comparison between the two experimental groups sometimes reached significance in favor of the L1-use group and at other times did not reach significance. The L2-only-definitions group never, however, outperformed the L1-use group. As for test time, Zhao \& Macaro's (2016) study showed better scores for the delayed post-test than the pre-test, and even higher scores for the immediate post-test. The picture was not as consistent in the current study. While the comparison of the pre-test and immediate post-test was consistently in favor of the post-test, the difference between the pre-test and the delayed post-test reached significance in favor of the delayed post-test only for the L1-use group. This is interpreted in terms of better long-term retrieval for L2 vocabulary learned via L1 mediation. As for the comparison between the immediate and delayed post-tests, statistical significance was in favor of the immediate post-test in almost half the conditions. Never did the delayed post-test scores were significantly higher than the immediate post-test.

As for Lotto \& De Groot (1998), the current study supports their findings highlighting the benefits of translation equivalents in L2 vocabulary learning. As for the effect of word type, Lotto \& De Groot (1998) showed effects of word type in terms of word frequency and cognate status. The current study defined word type differently in terms of concrete versus abstract nouns and action versus state verbs. All word types benefited from L1 use, similar to Zhao \& Macaro (2016), but the long-term retrieval was more facilitated for action verbs, which are generally classified as more concrete (e.g., Marian \& Kaushanskaya, 2007) than state verbs in line with the DFM. Similar facilitation for long-term retrieval was noted for abstract than concrete nouns in contrary to the DFM predictions. However, as explained earlier, the results may not contradict the DFM since students' interest in learning the specific abstract nouns in the current study may be understandably higher. In addition, the concreteness effect may appear more strongly at higher levels of proficiency and language experience.

It must also be noted that varied explanations for the L1-use advantage can be found in the literature. For example, Ramachandran \& Abdul Rahim (2004) referred to the importance of the L1 as a resource to overcome the limited L2 knowledge for beginning learners. They also highlighted that the L1 use could serve as a good learning strategy as it supports necessary cross-linguistic comparisons at different stages of learning. Another example is Zhao \& Macaro (2016) who described learning L2 words through L1 mediation as a "straightforward" process in comparison with the "complex" process of learning a new L2 word through L2-only-explanation which requires learners to comprehend a stream of L2 that may be too difficult for them, then infer the meaning of the new word which may be too cognitively demanding and then attempt to connect the new word with the relevant concept. Zhao \& Macaro (2016) also highlight the challenge of learning L2 words with sole reliance on L2 explanations due to the blurred semantic boundaries between the target word and its associates. They referred to the "fuzzy" nature of the semantic system with respect to family resemblance. They also explained the better long-term retrieval for learning based on L1 in terms of deeper processing of the new words.

\section{Pedagogical Implications \& Research Directions}

The current study highlights the benefit of explicit instruction for L2 vocabulary learning. The study also supports the benefits for L1 use in L2 vocabulary instruction. The researchers thus support the repeated call for the reconsideration of the role of L1 in the L2 classroom (e.g., Lee \& Macaro, 2013) especially in foreign language contexts. Current strict policies in different parts of the world that prohibit the use of the L1 in L2 classrooms regardless of the learners' proficiency levels, language learning experience, age, etc. must be reconsidered to match recent research findings. It is also important for language instructors to continuously recycle new vocabulary as the lower vocabulary gains in the current study may be attributed to the lack of vocabulary recycling. Likewise, it is important to consider the learners' level of interest in the new words as the learners' motivation may influence their learning. Other vocabulary learning techniques apart from L1 use and L2-only-definitions need to be carefully considered. The low learning gains for action verbs in the L2-only-definitions group in the current study may have been overcome with the use of pictures or modeling. 
Besides, the current study highlights the need for further research in relation to the L1 use. Most studies so far, including the present one, assesses vocabulary learning via receptive tests (e.g., MCQs and VKT). It will be interesting to examine the vocabulary gains in terms of productive tests (e.g., recall and gap-fill) to compare results. It will also be interesting to assess vocabulary gains in terms of online measures, such as measuring reaction times, and among varied levels of proficiency as increased proficiency may lead to different results. Another interesting area of research is to investigate other variables that can influence the optimal use of the L1, such as second-language versus foreign-language learning contexts (e.g., Al Sharareai, 2012). Differences in learning contexts may similarly lead to different findings. It is also recommended to examine the contextual conditions influencing the natural emergence of L1 in L2 learning classrooms (e.g., Moore, 2013, Thomspon, 2006; Millous, 2003) for consciousness raising and accurate assessment.

\section{Conclusion}

Based on earlier research highlighting the benefits of L1 use in support of L2 vocabulary learning (e.g., Khan, 2016; Pakzadian, 2012; Tian \& Macaro, 2012), the current study aimed to examine the L1 use from a relatively new direction. The study examined the effect of word type (defined in terms of concrete versus abstract nouns and action versus state verbs) on the L1 benefits. To this end, 130 Arabic-speaking female participants enrolled in EFL classes in preparation for university education were recruited for the study. The participants, who were elementary English language users, were divided into two experimental groups and one control group. The experimental groups learned 24 unfamiliar English words in 4 sessions over 4 weeks. One group was taught via L1 translation equivalents while the other group through L2 definitions. Meanwhile, the control group did not receive any special vocabulary treatment. The participants' scores on pre-, immediate post- and delayed post-tests were statistically analyzed using ANOVA and Bonferroni-corrected post hoc pairwise comparisons. The findings revealed the benefit of explicit vocabulary instruction via L1 or L2 as the experimental groups outperformed the control group in the two post-tests. The findings also showed an advantage for L1 use in long-term vocabulary retrieval as the L1-use group outperformed the L-only-definitions groups in vocabulary gains during the delayed post-test.

The findings of the current study support Kroll and Stewart's (1994) RHM and De Groot's (1993; 1992) DFM as elementary EFL learners seem to specially benefit from L1 mediation in learning L2 vocabulary as the two models predict. The current study also partially support the DFM prediction that concrete words would show stronger L1 benefits as the action verbs have showed stronger long-term gains than state verbs. However, concrete nouns failed to show a similar advantage probably due to the special nature of concrete and abstract stimuli used in the current study. The current study hence calls for a reconsideration of worldwide policies imposing the sole use of the target language in L2 classrooms regardless of the participants' characteristics, the features of the learning context and the nature of L2 vocabulary. It is wiser to adopt a mild version of the communicative teaching approach which allows principled use of L1. The current study also calls for further research on the optimal L1 use to explore pertinent determinants using a variety of vocabulary-learning assessment measures.

\section{Acknowledgements}

The researchers thank Prince Sultan University for supporting this research project through the research group [Language Learning and Teaching Research Group RG-CH-2016/11/11].

\section{References}

Ahmed, S. H. A. (2015). Exploring Sudanese secondary school teachers' attitudes towards the use of Arabic language in EFL classrooms. Journal of Humanities \& Social Science, 20(6), 72-77. https://doi.org/10.9790/0837-20657277

Al Sharaeai, W. A. A. (2012). Students' perspectives on the use of L1 in English classrooms. Graduate Theses and Dissertations. Paper 12898.

Altarriba, J., Bauer, L. M., \& Benevenuto, C. (1999). Concreteness, context availability, and imageability, and word associations for abstract, concrete, and emotion words. Behavior Research Methods, 31(4), 578-602. https://doi.org/10.3758/BF03200738

Aslikhosh, A., Alikhani, M. A., Alirezaeian, V., \& Bakhshi, H. (2014). Implementing L1 in teaching grammar. International Journal of Language Learning and Applied Linguistics World, 7(2), 81-92.

Barsalou, L. W. (1999). Perceptual symbol systems. Behavioral \& Brain Sciences, 22(4), 577-660. https://doi.org/10.1017/S0140525X99002149 
Berming, B. S. (2016). Can't I speak Japanese? The use of students' L1 as a cognitive tool for collaborative writing tasks in a Japanese EFL context. School of Education Student Capstones and Dissertations. Paper 4114. Retrieved from http://digitalcommons.hamline.edu/cgi/viewcontent.cgi?article=5113\&context=hse_all

Camó, A. C., \& Ballester, E. P. (2015). The effects of using L1 translation on young learners' foreign language vocabulary learning. Elia, 15, 109-134. http://dx.doi.org/10.12795/elia.2015.i15.06

Damra, H. M., \& Al Qudah, M. (2012). The effect of using native language on grammar achievement and attitudes towards learning of basic stages EFL students in Jordan. International Journal of Business and Social Science, 3(1), 300-306.

De Groot, A. M. B. (1992). Bilingual lexical representation: a closer look at conceptual representations. In R. Frost \& L. Katz (Eds.), Orthography, phonology, morphology, and meaning (pp. 389-412). Amsterdam: Elsevier. https://doi.org/10.1016/S0166-4115(08)62805-8

De Groot, A. M. B. (1992). Determinants of word translation. Journal of Experimental Psychology: Learning, Memory, and Cognition, 18(5), 1001-1018. http://dx.doi.org/10.1037/0278-7393.18.5.1001

De Groot, A. M. B. (1993). Word-type effects in bilingual processing tasks: Support for mixed representational system. In R. Schreuder \& B. Weltens (Eds.), The bilingual lexicon (pp. 27-51). Amsterdam: John Benjamins. http://dx.doi.org/10.1075/sibil.6.04gro

Debreli, E., \& Oyman, N. (2016). Students' preferences on the use of mother tongue in English as a foreign language classroom: Is it the time to re-examine English-only policies? English Language Teaching, 9(1), 148-162. http://dx.doi.org/10.5539/elt.v9n1p148

El-Dakhs, D. A. S. (2017). The effect of language exposure and word characteristics on the mental word associations in the second language: The case of Arabic-English bilinguals. Journal of Psycholinguistic Research. http://dx.doi.org/ 10.1007/s10936-017-9477-z

Fatemi, A. H., \& Barani, G. (2014). The impact of teachers' code-switching on the vocabulary learning of Iranian university EFL learners. Journal of Language Sciences \& Linguistics, 2(4), 91-98. https://doi.org/10.1016/j.sbspro.2014.03.551

Ghaiyoomian, H., \& Zarei, G. R. (2015). The effect of using translation on learning grammatical structures: A case study of Iranian junior high school students. Iranian Journal of Research in English Language Teaching, 3(1), 32-39.

Ghobadi, M., \& Ghasemi, H. (2015). Promises and obstacles of L1 use in language classrooms: A state-of-the-art review. English Language Teaching, 8(11), 245-254. http://dx.doi.org/10.5539/elt.v8n11p245

Hayati, M., \& Shahriari, A. (2010). The impact of L1 equivalents versus context on vocabulary recall of pre-university EFL students. The Journal of Teaching Language Skills, 2(3), 27-51. http://dx.doi.org/10.22099/JTLS.2012.414

Hennebry, M., Rogers, V., Macaro, E., \& Murphy, V. (2013). Direct teaching of vocabulary after listening: Is it worth the effort and what method is best? The Language Learning Journal. Retrieved from http://www.tandfonline.com/doi/abs/10.1080/09571736.2013.849751

Karimian, Z., \& Mohammadi, S. (2015). Teacher's use of first language in EFL classrooms. Journal of Applied Linguistics \& Language Research, 2(3), 61-71.

Kaushik, V. (2013). German for English speakers: The use of the L1 in L2 vocabulary acquisition. Unpublished Master's dissertation at the University of Calgary, Canada. Retrieved from http://theses.ucalgary.ca/bitstream/11023/980/2/ucalgary_2013_kaushik_vibha.pdf

Khan, M. S. (2016). The impact of native language use on second language vocabulary learning by Saudi EFL students. English Language Teaching, 9(5), 134-140. http://dx.doi.org/10.5539/elt.v9n5p134

Khansir, A. A., \& Tabande, Y. (2014). The effects of Persian language on vocabulary learning of Iranian EFL students. International Journal of Language Learning \& Applied Linguistic World, 6(3), 62-75.

Kim, Y. \& Yoon, H. (2014). The use of L1 as a writing strategy in L2 writing tasks. GEMA Online Journal of Language Studies, 14(3), 33-50. http://dx.doi.org/10.17576/GEMA-2014-1403-03

Krashen, S. D. (1985). The input hypothesis: Issues and implications. London: Longman.

Kroll, J. F., \& Stewart, E. (1994). Category interference in translation and picture naming: Evidence for 
asymmetric connections between bilingual memory representations. Journal of Memory and Language, 33(2), 149-174. https://doi.org/10.1006/jmla.1994.1008

Latsanyphone, S., \& Bouangeune, S. (2009). Using L1 in teaching vocabulary to low English proficiency level students: A case study at the National University of Laos. English Language Teaching, 2(3), 186-193.

Lee, J. H., \& Macaro, E. (2013). Investigating age in the use of L1 on English-only instruction: Vocabulary acquisition by Korean EFL learners. The Modern Language Journal, 97(4), 887-901. http://doi.org/10.1111/j.1540-4781.2013.12044.x

Liu, J. (2008). L1 use in L2 vocabulary learning: Facilitator or barrier. International Education Studies, 1(2), 65-69. http://dx.doi.org/10.5539/ies.v $1 n 2$ p65

Long, M. H. (1996). The role of the linguistic environment in second language acquisition. In W. C. Ritchie \& T. K. Bhatia (Eds.), Handbook of second language acquisition (pp. 413-468). San Diego, CA: Academic Press. https://doi.org/10.1016/B978-012589042-7/50015-3

Lotto, L., \& de Groot, A. M. B. (1998). Effects of learning method and word type on acquiring vocabulary in an unfamiliar language. Language Learning, 48(1), 31-69. https://doi.org/ 10.1111/1467-9922.00032

Ma, L. P. F. (2009). Attitudes of adult Chinese-background learners and an ESL teacher towards L1 use in an AMEP class in Australia. University of Sydney Papers in TESOL, 4, 57-84.

Marian, V., \& Kaushanskaya, M. (2007). Cross-linguistic transfer and borrowing in bilinguals. Applied Psycholinguistics, 28(2), 369-390. https://doi.org/10.1017/S014271640707018X

Meara, P. (1980). Vocabulary acquisition: A neglected aspect of language learning. Language Teaching and Linguistics Abstracts, 13, 221-246. https://doi.org/10.1017/S0261444800008879

Millous, C. (2003). Using L1 and L2 effectively in the foreign language classroom. MA TESOL Collection. Paper 178.

Mohebi, H., \& Alavi, S.M. (2014). An investigation into teachers' first language use in a second language learning classroom context: A questionnaire-based study. Bellaterra Journal of Teaching \& Learning Language \& Literature, 7(4), 57-73.

Moore, P. J. (2013). An emergent perspective on the use of the first language in the English-as-a-foreign-language classroom. The Modern Language Journal, 97(1), 239-253. https://doi.org/10.1111/j.1540-4781.2013.01429.x

Nakatsukasa, K., \& Loewen, S. (2015). A teacher's first language use in form-focused episodes in Spanish as a foreign language classroom. Language Teaching Research, 19(2), 133-149. https://doi.org/10.1177/1362168814541737.

Nation, I. S. P. (2001). Learning vocabulary in another language. Cambridge: Cambridge University Press. https://doi.org/10.1017/CBO9781139524759

Nazary, M. (2008). The role of L1 in L2 acquisition: Attitudes of Iranian university students. Novitas-Royal Research on Youth and Language, 2(2), 138-153.

Oxford, R. L. (1990). Language learning strategies: What every teacher should know. Boston, Mass.: Heinle and Heinle Publishers.

Pakzadian, M. (2012). The effect of L1 on learning new L2 vocabulary among intermediate proficiency level students. Theory \& Practice in Language Studies, 2(6), 1147-1152. https://doi.org/10.4304/tpls.2.6.1147-115

Ramachandran, S. D., \& Abdul Rahim, H. (2004). Meaning recall and retention: The impact of the translation method on elementary level learners' vocabulary learning. RELC Journal, 35(2), 161-178. https://doi.org/10.1177/003368820403500205

Schmitt, N. (2000). Vocabulary in language teaching. Cambridge: Cambridge University Press.

Segalowitz, N., \& De Almeida, R. G. (2002). Conceptual representation of verbs in bilinguals: Semantic field effects and a second-language performance paradox. Brain \& Language, 81(1-3), 517-531. https://doi.org/10.1006/brln.2001.2544

Swain, M. (1995). Three functions of output in second language learning. In G. Cook \& B. Seidlhofer (Eds.), Principles and practice in applied linguistics: Studies in honour of H.G. Widdowson (pp. 125-144). Oxford: Oxford University Press. 
Thomspon, G. L. (2006). Teacher and student first language and target language use in the foreign language classroom: A qualitative and quantitative study of language choice. Unpublished doctoral dissertation of the University of Arizona, USA. from http://arizona.openrepository.com/arizona/bitstream/10150/194958/1/azu_etd_1705_sip1_m.pdf

Tian, L., \& Macaro, E. (2012). Comparing the effect of teacher code-switching with English-only explanations on the vocabulary acquisition of Chinese university students: A lexical focus-on-form study. Language Teaching Research, 16(3), 367-391. https://doi.org/ 10.1177/1362168812436909

Turnbull, M., \& Dailey-O'Cain, J. (Eds.) (2009). First language use in second and foreign language learning. Bristol, UK: Multilingual Matters.

Van Hell, J. G., \& Mahn, A. C. (1997). Keyword mnemonics versus rote rehearsal: Learning concrete and abstract foreign words by experienced and inexperienced learners. Language Learning, 47(3), 507-546. https://doi.org/ 10.1111/0023-8333.00018

Zhao, T., \& Macaro, E. (2016). What works better for the learning of concrete and abstract words: Teachers' L1 use or L2-only explanations? International Journal of Applied Linguistics, 26(1), 75-98. https://doi.org/10.1111/ijal.12080

Zimmerman, C. B. (1997). Historical trends in second language vocabulary instruction. In J. Coady \& T. Huckin (Eds.), Second language vocabulary acquisition (pp. 5-19). Cambridge: Cambridge University Press.

\section{Appendix A}

\section{Sample of the Study Vocabulary Test}

Instructions (provided in English and Arabic for the participants)

Read the words in the left-hand column of the table below. Tick (??) the option that best describes your word knowledge in the right-hand column. If you choose item (3), you need to tick the right category to classify the words. If you choose item (4), you need to write the meaning of the words in Arabic or English.

\begin{tabular}{|l|l|ll|}
\hline 1. & Wit & O & 1. I've never seen this word before. \\
& & 2. I've seen this word, but I don't know what it means. \\
& & 3. I've seen this word, and it belongs to the following category: \\
& \\
& & 4. I know this word, and it means: \\
&
\end{tabular}

\section{Appendix B}

\section{Study Stimuli}

\begin{tabular}{|l|l|l|l|l|}
\hline Word Type & Concrete Nouns & Abstract Nouns & Action Verbs & Abstract Verbs \\
\hline Theme & Objects & Personality Traits & Actions & Feelings \\
\hline Stimuli & Curio & Brutality & Collapse & Astound \\
& Figurine & Patriotism & Compile & Loathe \\
& Trinket & Integrity & Escalate & Yearn \\
& Chimes & Perseverance & Generate & Desire \\
& Hatchet & Contentment & Manipulate & Adore \\
& Easel & Graciousness & Purchase & Satisfy \\
\hline
\end{tabular}

\section{Copyrights}

Copyright for this article is retained by the author(s), with first publication rights granted to the journal.

This is an open-access article distributed under the terms and conditions of the Creative Commons Attribution license (http://creativecommons.org/licenses/by/4.0/). 